\title{
Tema Post-Modern pada Perencanaan Desain Stasiun Intermoda LRT (Light Rail Transit) Joyoboyo sebagai Local Icon di Surabaya
}

\author{
Dian Arminda ${ }^{1}$, Siti Azizah ${ }^{2}$ \\ ${ }^{1}$ Jurusan Arsitektur, Fakultas Teknik Sipil dan Perencanaan, Institut Teknologi Adhi Tama Surabaya \\ ${ }^{2}$ Jurusan Arsitektur, Fakultas Teknik Sipil dan Perencanaan, Institut Teknologi Adhi Tama Surabaya \\ Email: ${ }^{1}$ dianarminda@gmail.com
}

\begin{abstract}
As we know, Surabaya occupies the second position as a city that has the most populous vehicle volume after Jakarta. Lack of public transportation services makes people choose to use private vehicles and even online transportation which of course will just cause traffic jams. Some things that make people less use public transportation include low levels of comfort, safety, punctuality, and discipline in driving, as well as inadequate transportation. Congestion is triggered by the increasing number of vehicles and is not comparable with the development of existing infrastructure. Of the many problems that have arisen, the central government and regional governments plan for an adequate and mass-based transportation infrastructure namely LRT (Light Rail Transit) that is able to transport passengers in large numbers, fast, and rail-based that is able to give the impression of being safe, comfortable, and clean. Comfort for passengers is not only when riding the LRT train, but at the station. The station is made as comfortable as possible so that it can attract visitors to prefer using public transportation rather than private vehicles or online transportation by providing facilities in the form of commercial areas and other supporting facilities. Macro concept on LRT Station design carries a concept of "Transit in Leisure" and "Iconic". This concept was raised so that visitors feel comfortable when using public transportation such as LRT. So, it can attract the interest of the public to want to move transportation facilities from private transportation and online transportation to public transportation. With the existence of several supporting facilities, it is expected to be a special attraction for the transportation user community. Of course this is done to attract the interest of people in all circles to use public transportation such as LRT. The facilities provided are the presence of green open space, retail, cafeteria, food court, health and spa, playground, and roof garden. This is expected to be able to change the mindset of station users where usually people who are mobile are always as if being chased by time so they feel pressured. With the facilities mentioned above, it is hoped that users can enjoy their mobility more. Creating LRT Station building design with elevated station characteristics requires the main structure that can be used to prioritize reinforcement and sturdiness in LRT Station buildings that are attractively packaged and make LRT Station buildings an icon in Surbaya City is an embodiment of a form to display something new and different from other buildings, but still pay attention to the surrounding environment. So the building has its own charm and becomes a local icon in Surabaya.
\end{abstract}

Keywords: Intermodal Station LRT (Light Rail Transit), Local Icon, Transit In Leisure, Iconic, post modern architecture

\begin{abstract}
Abstrak. Seperti yg kita tau, Surabaya menduduki posisi kedua sebagai kota yang memiliki volume kendaraan terpadat setelah Jakarta. Kurangnya layanan transportasi umum membuat masyarakat memilih menggunakan kendaraan pribadi bahkan transportasi online yang tentunya sama saja akan menimbulkan kemacetan. Beberapa hal yang membuat masyarakat kurang menggunakan kendaraan umum antara lain rendahnya tingkat kenyamanan, keamanan, ketepatan waktu, dan kedisiplinan dalam berkendara, serta transporasi yang ada belum memadai. Kemacetan dipicu dengan jumlah kendaraan yang semakin meningkat dan tidak sebanding dengan pembangunan infrastruktur yang ada. Dari banyaknya permasalah yang muncul, pemerintah pusat dan pemerintah daerah merencanakan adanya infrastruktur transportasi yang memadai dan berbasis massal yaitu LRT (Light Rail Transit) yang mampu mengangkut penumpang dalam jumlah yang banyak, cepat, dan berbasis rel yang mampu memberikan kesan aman, nyaman, dan bersih. Kenyaman bagi para penumpang tidak hanya saat menaiki kereta LRT saja, namun pada stasiun. Stasiun dibuat senyaman mungkin sehingga mampu menarik minat pengunjung untuk lebih memilih menggunakan transportasi umum daripada kendaraan pribadi atau transportasi online dengan menyediakan fasillitas berupa area komersil dan fasilitas
\end{abstract}


penunjang lainnya. Konsep makro pada desain Stasiun LRT mengusung sebuah konsep "Transit In Leisure" dan "Iconic". Konsep ini diangkat agar para pengunjung merasa nyaman saat menggunakan transportasi umum seperti LRT. Sehingga, dapat menarik minat masyarakat untuk mau berpindah sarana transportasi dari transportasi pribadi dan transportasi online ke transportasi umum. Instalasi beberapa fasilitas penunjang diharapkan dapat menjadi daya tarik tersendiri bagi masyarakat pengguna transportasi. Tentunya hal ini dilakukan untuk menarik minat masyarakat dalam semua kalangan agar menggunakan transportasi umum seperti LRT. Fasilitas yang disediakan yaitu adanya fasilitas ruang terbuka hijau, retail, cafeteria, food court, helat and spa, taman bermain, dan roof garden. Hal ini diharapkan mampu merubah pola pikir pengguna stasiun dimana biasanya orang yang bermobilitas selalu seakan-akan dikejar oleh waktu sehingga merasa tertekan. Dengan adanya fasilitas-fasilitas yang telah disebutkan diatas, diharapkan pengguna dapat lebih menikmati mobilitas mereka. Menciptakan desain bangunan Stasiun LRT dengan memiliki karakteristik stasiun layang membutuhkan struktur utama yang mampu digunakan untuk mengutamakan perkuatan dan kekokohan pada bangunan Stasiun LRT yang dikemas secara menarik dan menjadikan bangunan Stasiun LRT menjadi icon di Kota Surbaya merupakan perwujudan bentuk untuk menampilkan sesuatu yang baru dan berbeda dari bagunan lainnya, namun tetap memperhatikan lingkungan sekitarnya. Sehingga bangunan memiliki daya tarik sendiri dan menjadi local icon di Surabaya.

Kata Kunci: Stasiun Intermoda LRT (Light Rail Transit), Local Icon, Transit In Leisure, Iconic, Arsitektur Post Modern

\section{Pendahuluan}

Seperti yang kita tau, Surabaya menduduki posisi kedua sebagai kota yang memiliki volume kendaraan terpadat setelah Jakarta. Kurangnya layanan transportasi umum membuat masyarakat memilih menggunakan kendaraan pribadi bahkan transportasi online yang tentunya sama saja akan menimbulkan kemacetan. Beberapa hal yang membuat masyarakat kurang menggunakan kendaraan umum antara lain rendahnya tingkat kenyamanan, keamanan, ketepatan waktu, dan kedisiplinan dalam berkendara, serta transporasi yang ada belum memadai. Kemacetan dipicu dengan jumlah kendaraan yang semakin meningkat dan tidak sebanding dengan pembangunan infrastruktur yang ada.

Dari banyaknya permasalah yang muncul, pemerintah pusat dan pemerintah daerah merencanakan adanya infrastruktur transportasi yang memadai dan berbasis massal yaitu LRT (Light Rail Transit) yang mampu mengangkut penumpang dalam jumlah yang banyak, cepat, dan berbasis rel yang mampu memberikan kesan aman, nyaman, dan bersih. Kenyaman bagi para penumpang tidak hanya saat menaiki kereta LRT saja, namun pada stasiun. Stasiun dibuat senyaman mungkin sehingga mampu menarik minat pengunjung untuk lebih memilih menggunakan transportasi umum daripada kendaraan pribadi atau transportasi online dengan menyediakan fasillitas berupa area komersil dan fasilitas penunjang lainnya.

Dengan adanya fasilitas-fasilitas yang disediakan, diharapkan pengguna dapat lebih menikmati mobilitas mereka. Menciptakan desain bangunan Stasiun LRT dengan memiliki karakteristik stasiun layang membutuhkan struktur utama yang mampu digunakan untuk mengutamakan perkuatan dan kekokohan pada bangunan Stasiun LRT yang dikemas secara menarik dan menjadikan bangunan Stasiun LRT menjadi icon di Kota Surbaya merupakan perwujudan bentuk untuk menampilkan sesuatu yang baru dan berbeda dari bagunan lainnya, namun tetap memperhatikan lingkungan sekitarnya. Sehingga bangunan memiliki daya tarik sendiri dan menjadi local icon di Surabaya.

Dari latar belakang tersebut, permasalahan yang muncul adalah bagaimana merencanakan dan merancang sebuah Stasiun Intermoda LRT (Light Rail Transit) Joyoboyo sebagai Local Icon di Surabaya yang mampu menampilkan unsur postmodern kontekstual. Bukan hanya itu, bangunan tersebut juga harus memiliki fasad dengan daya tarik dan kokoh yang dikemas semenarik mungkin. Secara fungsional, terdapat permasalahan mengenai bagaimana merancang sebuah Stasiun Intermoda LRT (Light Rail Transit) Joyoboyo sebagai Local Icon di Surabaya yang mampu memfasilitasi masyrakat dalam bertransportasi agar masyrakat nyaman saat bermobilitas.

Hasil dari perencanaan konsep ini memiliki tujuan agar dapat memfasilitasi dan melayani dengan mode transportasi umum yang cepat, aman dan nyaman bagi penggunannya, sehingga aktivitas masyarakat terbantu dan terlayani dengan baik karena adanya transportasi massal yang berbasis rel- 
LRT (Light Rail Transit) Joyoboyo yang terintergrasi dengan moda transportasi umum lainnya. Manfaat dari perencanaan konsep desain ini adalah untuk memberikan masukan desain untuk fasilitas transportasi umum, sehingga meminimalisir kemacetan dan beberapa masalah lainnya, serta diharapkan kedepannya masyarakat lebih memilih menggunakan transportasi umum daripada kendaraan pribadi.

\subsection{Tinjauan Pustaka}

Dengan adanya rencana pembangunan LRT, tentu saja membutuhkan beberapa stasiun sebagai tempat yang mewadahi pendukung kelancaran pembangunan LRT. Salah satu stasiun yang dibutuhkan berada di lokasi Joyoboyo. Nantinya Joyoboyo akan menjadi kawasan pusat transportasi Kota Surabaya. Menciptakan desain bangunan Stasiun LRT dengan memiliki karakteristik stasiun layang membutuhkan struktur utama yang mampu digunakan untuk mengutamakan perkuatan dan kekokohan pada bangunan Stasiun LRT yang dikemas secara menarik dan menjadikan bangunan Stasiun LRT menjadi icon di Kota Surbaya merupakan perwujudan bentuk untuk menampilkan sesuatu yang baru dan berbeda dari bagunan lainnya, namun tetap memperhatikan lingkungan sekitarnya. Sehingga bangunan memiliki daya tarik sendiri dan menjadi local icon di Surabaya.

\subsection{Metode Penelitian}

Jenis metode yang digunakan dalam menyusun Stasiun Intermoda LRT (Light Rail Transit) Joyoboyo sebagai Local Icon di Surabaya ini menggunakan jenis penelitian deskriptif kualitatif (Observasi, Interview, analisa data, dokumentasi).

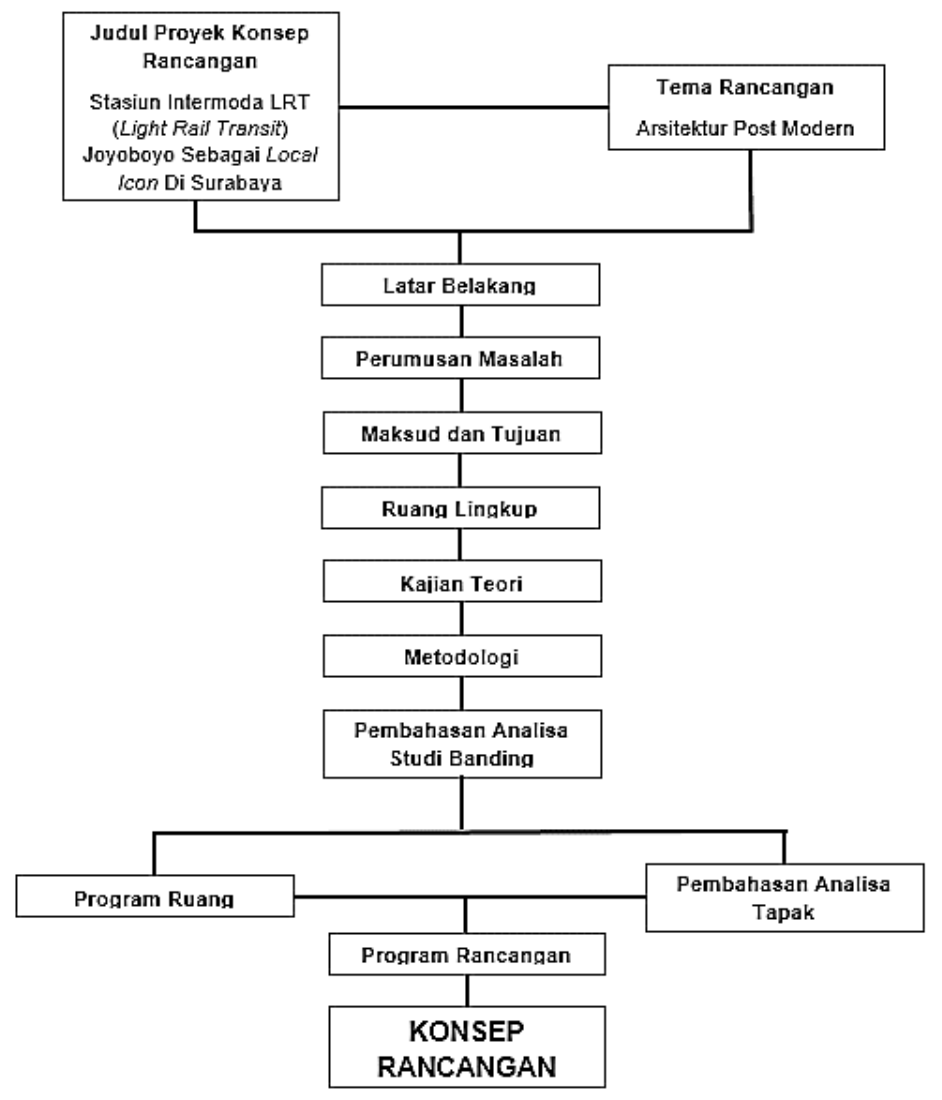

Gambar 1. Diagram metodologi

\section{Pembahasan}

Pembahasan ini menyajikan proses perencanaan konsep desain, yang terdiri dari penyusunan program ruang, zonasi ruang dan zonasi kebutuhan ruang, telaah lokasi, hingga hasil berupa konsep rancangan dari Stasiun Intermoda LRT. 


\subsection{Program Ruang}

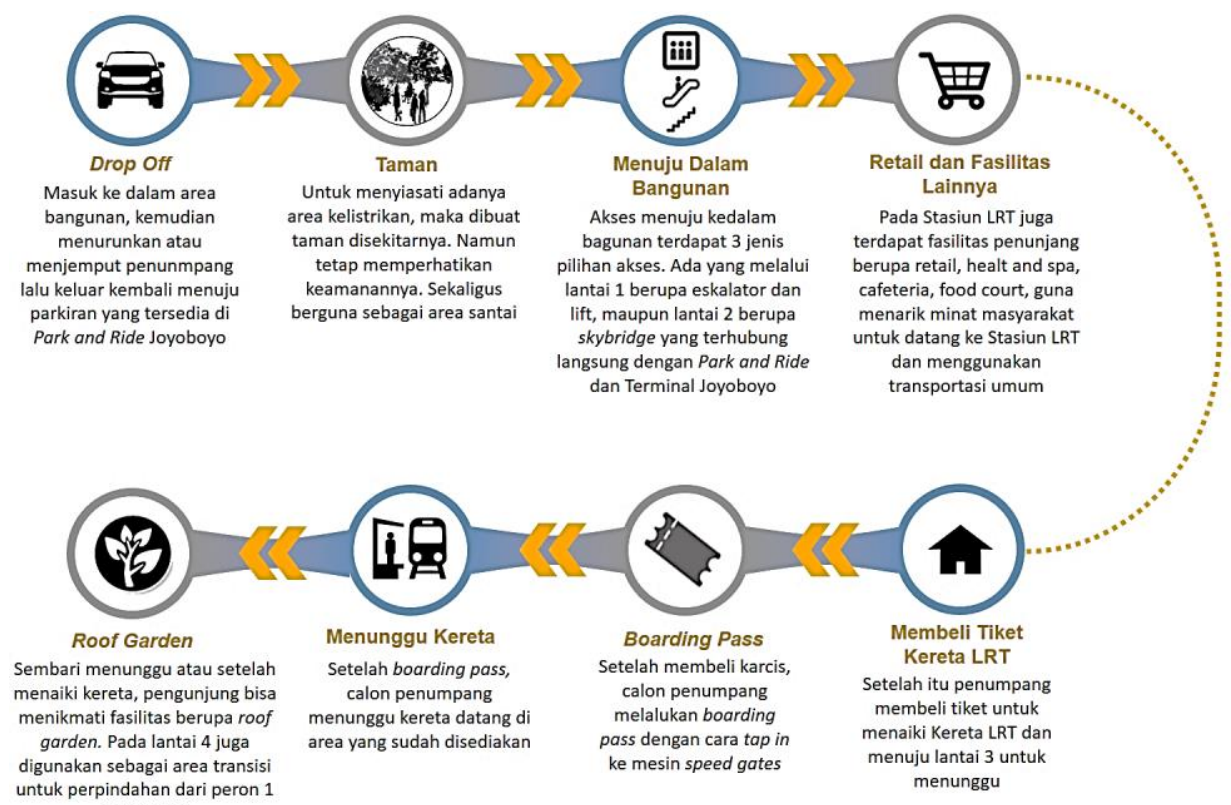

Gambar 2. Aktivitas yang dilakukan

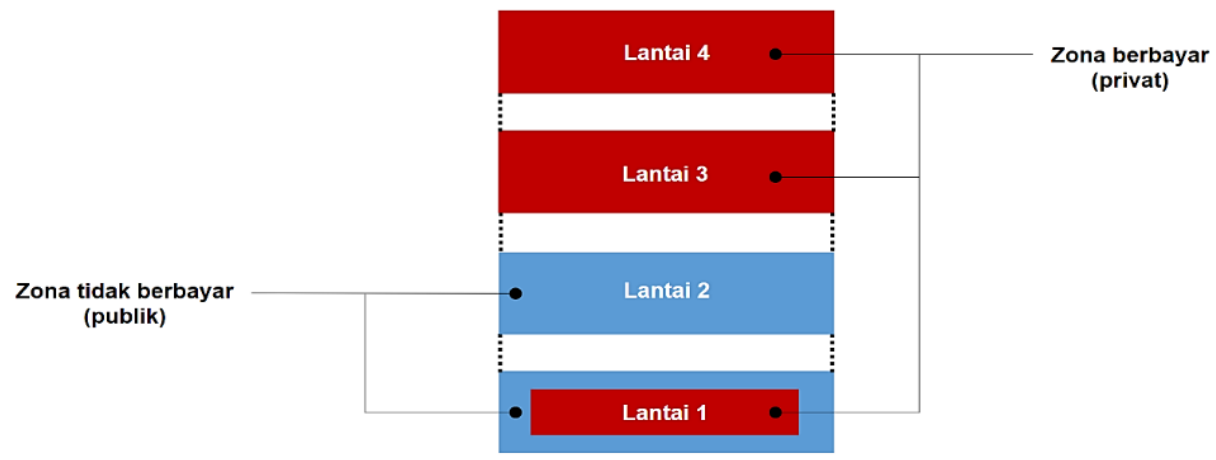

Gambar 3. Zonasi ruang publik dan ruang privat

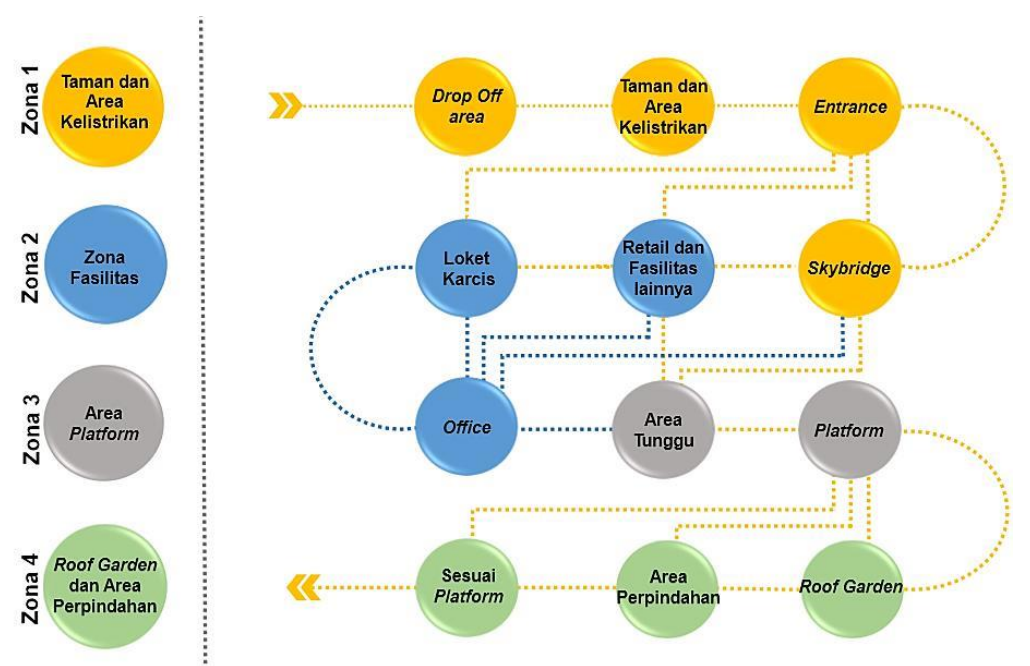

Gambar 4. Zonasi kebutuhan ruang 


\subsection{Telaah Lokasi}

Site berlokasi di sebelah utara dari Terminal Joyoboyo dan Park and Ride Joyoboyo. Kondisi eksisting dan site ini adalah permukiman kumuh penduduk lokal yang sebagian besar memiliki mata pencahariaan sebagai penjual cenderamata Kebun Binatang Surabaya. Pemilihan lokasi itu sendiri juga berdasarkan data yang sudah ada di BAPPEKO Surabaya dan sesuai dengan rancangan Stasiun LRT di Surabaya.

\begin{tabular}{ll}
\hline Nomor & \multicolumn{1}{c}{ Stasiun } \\
\hline TB1 & Lidah Kulon \\
\hline TB2 & UNESA \\
\hline TB3 & Lontar \\
\hline TB4 & Simpang Darmo Permai \\
\hline TB5 & HR. Muhammad \\
\hline TB6 & Bundaran Satelit \\
\hline TB7 & Dukuh Kupang \\
\hline TB8 & Pakis \\
\hline TB9 & Adityawarman \\
\hline TB9 & Joyoboyo \\
\hline TB10 & Indragiri \\
\hline TB11 & Dr. Sutomo \\
\hline TB12 & St. Louis \\
\hline TB13 & Keputron \\
\hline
\end{tabular}

\begin{tabular}{ll}
\hline Nomor & \multicolumn{1}{c}{ Stasiun } \\
\hline$T B 14$ & Parkir Timur Plaza Surabaya \\
\hline$T B 15$ & Stasiun Gubeng \\
\hline$T B 16$ & RSDr. Soetomo \\
\hline$T B 17$ & Dhormahusada \\
\hline$T B 18$ & UNAIR Kampus C \\
\hline$T B 19$ & Dhormahusada Indoh Timur \\
\hline$T B 20$ & GOR Kertajaya Indoh \\
\hline$T B 21$ & ITS \\
\hline$T B 22$ & Mulyosari \\
\hline$T B 23$ & Kejawan \\
\hline$T B 24$ & Keputih \\
\hline$T B 25$ & Keputih Depo
\end{tabular}

Gambar 5. Rincian jalur LRT di Surabaya

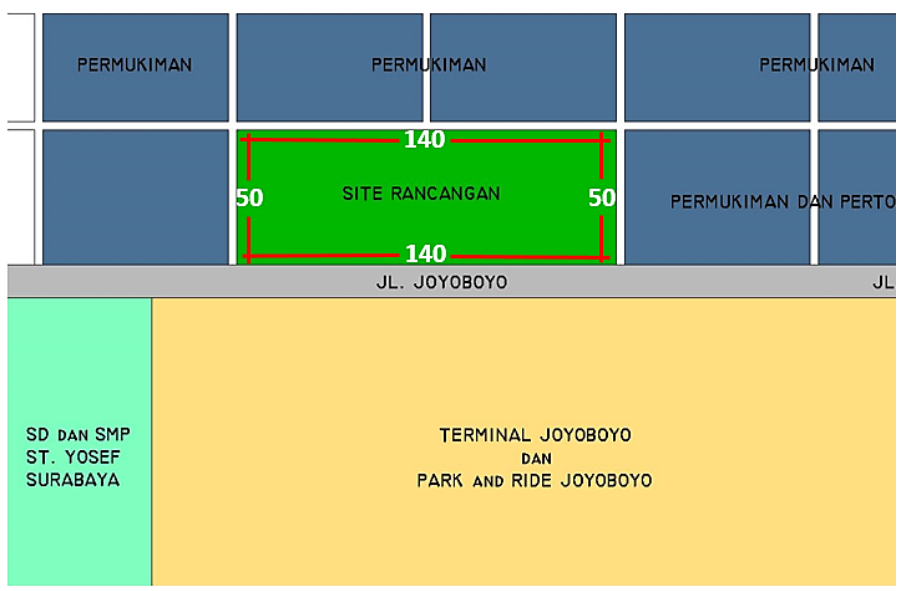

Gambar 6. Lokasi tapak

\subsection{Konsep Rancangan}

Konsep rancangan ini menceritakan mulai dari penarikan makro konsep "simiotica", mengerucut hingga mikro konsep "integrated" pada lahan, "comformity" pada bentuk, dan "invormative" pada ruang.

\subsubsection{Makro Konsep "Transit in Leisure" dan "Iconic"}

Konsep makro pada desain Stasiun LRT mengangkat sebuah konsep "Transit In Leisure" dan "Iconic". Konsep ini diangkat agar para pengunjung merasa nyaman saat menggunakan transportasi umum seperti LRT. Sehingga, dapat menarik minat masyarakat untuk mau berpindah sarana transportasi dari transportasi pribadi dan transportasi online ke transportasi umum. Dengan adanya beberapa fasilitas penunjang diharapkan dapat menjadi daya tarik tersendiri bagi masyarakat pengguna transportasi. Tentunya hal ini dilakukan untuk menarik minat masyarakat dalam semua kalangan agar menggunakan 
transportasi umum seperti LRT. Fasilitas yang disediakan yaitu adanya fasilitas ruang terbuka hijau, retail, cafeteria, food court, helat and spa, taman bermain, dan roof garden. Hal ini diharapkan mampu merubah pola pikir pengguna stasiun dimana biasanya orang yang bermobilitas selalu seakan-akan dikejar oleh waktu sehingga merasa tertekan. Dengan adanya fasilitas-fasilitas yang telah disebutkan diatas, diharpkan pengguna dapat lebih menikmati mobilitas mereka. Menciptakan desain bangunan Stasiun LRT dengan memiliki karakteristik stasiun layang membutuhkan struktur utama yang mampu digunakan untuk mengutamakan perkuatan dan kekokohan pada bangunan Stasiun LRT yang dikemas secara menarik dan menjadikan bangunan Stasiun LRT menjadi icon di Kota Surabaya merupakan perwujudan bentuk untuk menampilkan sesuatu yang baru dan berbeda dari bagunan lainnya, namun tetap memperhatikan lingkungan sekitarnya. Sehingga bangunan memiliki daya tarik sendiri dan menjadi local icon di Surabaya.

\subsubsection{Mikro Konsep Tatanan lahan "Integrated"}

Konsep tatanan lahan mengusung sebuah konsep "Integrated". Konsep ini diangkat untuk memberikan ruang dalam melakukan aktivitas bertransportasi untuk mengunakan moda transportasi satu ke moda transprtasi lainnya. Menyediakan fasilitas berupa skybridge guna menghubungkan antara Stasiun dengan Terminal untuk memfasilitasi intermoda pada transportasi. Tidak hanya menyediakan fasilitas untuk beraktivitas bertransportasi saja, namun menyediakan fasilitas penunjang lainnya untuk meningkatkan kenyamanan sehingga mampu menarik minat orang lain untuk mengunakan transportasi.

\subsubsection{Mikro Konsep Bentuk "Comformity"}

Konsep bentuk mengambil sebual konsep "Conformitiy". Konsep ini diangkat dengan bentuk bangunan yang ikonik membuat desain bangunan menjadi berbeda dengan bangunan lainnya, namun tetap selaras dengan lingkungan sekitarnya. Sehingga menarik pandangan mata orang yang melihat. Selain itu dengan desain yang berbeda seperti ini juga mempermudah orang dalam mencari stasiun (membedakan bangunan stasiun dengan bangunan yang lain).

\subsubsection{Mikro Konsep Ruang "Invormative"}

Konsep ruang mengusung sebuah konsep "Informative". Konsep ini diangkat karena pada bangunan Stasiun LRT menggunakan teknologi dan seluruh aktivitas utama dilakukan didalam ruangan. Dari segi penataan ruang yang tepat sesuai dengan segala urutan aktivitas yang ada dan sirkulasi pengunjung akan terarah secara otomatis. Sehingga konsep informative dapat mewujudkan ruang yang nyaman, dari segi zona yang jelas, penataan ruang yang baik, dan teknologi yang efisien.

\section{Kesimpulan}

Stasiun Intermoda LRT (Light Rail Transit) Joyoboyo Sebagai Local Icon di Surabaya yang bertujuan untuk mewadahi aktivitas bertransportasi dengan nyaman, aman, cepat, dan terintegrasi dengan moda transportasi lainnya agar masyarakat menikmati mobilitas mereka. Dengan didukungnya beberapa fasilitas penunjang diharapkan mampu menarik miat masyarakat.

Stasiun Intermoda LRT (Light Rail Transit) Joyoboyo Sebagai Local Icon di Surabaya merupakan bangunan Stasiun LRT dengan memiliki karakteristik stasiun layang membutuhkan struktur utama yang mampu digunakan untuk mengutamakan perkuatan dan kekokohan pada bangunan Stasiun LRT yang dikemas secara menarik dan menjadikan bangunan Stasiun LRT menjadi icon di Kota Surbaya merupakan perwujudan bentuk untuk menampilkan sesuatu yang baru dan berbeda dari bagunan lainnya, namun tetap memperhatikan lingkungan sekitarnya. Sehingga bangunan memiliki daya tarik sendiri dan menjadi local icon di Surabaya.

Adanya bangunan Stasiun LRT ini diharapkan mampu menarik minat masyarakat untuk menggunakan transportasi umum dan mampu merubah pola pikir masyarakat agar mau beralih menggunakan transportasi umum daripada kendaraan pribadi atau transportasi online. Selain itu, lokasi Stasiun LRT juga bertepatan di Joyoboyo, dimana nantinya Joyoboyo ini akan menjadi pusat transportasi di Surabaya dan mampu memfasilitasi intermoda dalam bertransportasi mulai dari menggunakan moda transportasi satu ke moda transportasi lainnya. 


\section{Referensi}

Story, Surabaya. 2018. Menunggu Wajah Baru Joyoboyo Jadi Terminal Modern Surabaya. Diakses dari https://surabayastory.com/2018/09/17/menunggu-wajah-baru-joyoboyo-jadi-terminalmodern-surabaya. Tanggal 1 Oktober 2019

Faril. 2011. Aliran dalam langgam arsitektur post modern. Diakses dari http://fariable.blogspot.com/2011/08/aliran-dalamlanggam-arsitektur-post.html. Tanggal 7 Oktober 2019

Badan Perencanaan Pembangunan Kota Surabaya. "SMART (Surabaya Integrated Mass Rapid Transit)". Booklet AMC Kota Surabaya

Dinas Perhubungan Surabaya. Grafik Pertumbuhan Kendaraan Pribadi 2010-2014. 
